\title{
COMPARISON OF EFFECTS OF PROTAMINE AND POLYBRENE, WITH SPECIAL EMPHASIS ON THE FACTOR VIII (ANTI- HEMOPHILIC GLOBULIN) DEFICIENCY INDUCED *
}

\author{
By HERBERT A. PERKINS, GEORGE HARKINS, FRANK GERBODE, \\ MARY R. ROLFS AND D. J. ACRA \\ (From the Research Laboratory of the Irwin Memorial Blood Bank of the San Francisco \\ Medical Society, and the Surgical Research Laboratory of the Presbyterian \\ Medical Center, San Francisco, Calif.)
}

(Submitted for publication November 17, 1960; accepted April 6, 1961)

Successful achievement of extracorporeal circulation requires that blood coagulability be temporarily interrupted during perfusion and afterward restored to normal. Heparin is accepted as the drug of choice in rendering the blood incoagulable, but there are two drugs, protamine and Polybrene (hexadimethrine bromide), available for effective in vivo neutralization of heparin, and controversy exists as to which of these should be used. In an effort to determine which of these heparin antagonists is superior, comparative studies on protamine and Polybrene were carried out to evaluate heparin neutralization, physiological and hematological effects, and such other matters as may be of practical importance.

In the course of these studies an unexpected fact became apparent. The intravenous injection of protamine or Polybrene resulted in a coagulation factor deficiency, persisting long after the temporary anticoagulant effect of the heparin neutralizer had disappeared. It was possible to demonstrate that a striking loss of Factor VIII (antihemophilic globulin) had been induced.

\section{METHODS}

Adult mongrel dogs were used throughout the study, and all animals were anesthetized with intravenous Nembutal (pentobarbital), $30 \mathrm{mg}$ per $\mathrm{kg}$. A measured dose of protamine ${ }^{1}$ or Polybrene ${ }^{2}$ (up to levels of $5 \mathrm{mg}$ per $\mathrm{kg}$ ) was rapidly injected into the inferior vena cava through a polyethylene catheter in the femoral vein and the tubing immediately flushed with $10 \mathrm{ml}$ of normal saline. All samples were taken in a siliconized syringe from a catheter inserted into the femoral artery with its tip in

* Aided by grants from the National Institutes of Health, Bethesda, Md. Abstracts of material included in this article have been previously published $(1,2)$.

1 One per cent solution, Lilly.

2 One per cent solution, Abbott. the aorta. Prior to each sampling the tubing was first cleared of stagnant blood by removal of $10 \mathrm{ml}$ of blood.

In experiments that did not require repeated withdrawal of blood samples, the two drugs were tested 8 weeks apart in the same animal under identical conditions, thereby allowing each animal to serve as its own control. In all other experiments the two were tested simultaneously in different animals.

Pulse and blood pressure recordings were made through a strain gauge connected to a femoral arterial catheter. Respirations were charted by means of a spirometer connected to a cuffed endotracheal tube. Standard limb lead electrocardiograms were taken.

Protamine and Polybrene levels were measured by heparin titrations, which were performed in some experiments by adding $1 \mathrm{ml}$ of blood from the syringe to each of a row of $12 \times 75 \mathrm{~mm}$ glass tubes in a water bath at $37^{\circ} \mathrm{C}$. Each tube contained $0.1 \mathrm{ml}$ of heparin in amounts of 0 to $50 \mu \mathrm{g}$ at increments of $5 \mu \mathrm{g}$. Each tube was immediately capped with Parafilm and inverted twice to mix the contents. They were observed for clotting at intervals of 1 minute, the endpoint being a clot which remained solid on tipping the tube past horizontal and tapping it gently against the side of the water bath. The neutralization point was taken as the tube with the greatest amount of heparin in which the shortest clotting time occurred.

In other experiments the titrations were done on plasma from blood collected in 0.1 vol of 3.8 per cent sodium citrate. Each tube contained $0.1 \mathrm{ml}$ of heparin in concentrations of 0 to $10 \mu \mathrm{g}$ at increments of $1 \mu \mathrm{g}$ plus $0.1 \mathrm{ml}$ of the plasma to be tested. Then $0.1 \mathrm{ml}$ of $0.025 \mathrm{M}$ calcium chloride was added in rapid succession to each tube, they were mixed, and observed for clotting at intervals of one-half minute. Repeated titrations on the same sample over a period of 6 hours gave the same results.

Lee-White clotting times were done by placing $2 \mathrm{ml}$ of blood in each of three $12 \times 75 \mathrm{~mm}$ Pyrex tubes in the water bath. The endpoint was taken as the time at which the third tube could be tipped past horizontal without displacing the clot.

Platelet counts were performed on 5-ml blood samples collected in a $15 \mathrm{ml}$ polyethylene vial containing 0.2 $\mathrm{ml}$ of 10 per cent disodium ethylenediamine tetraacetic 
acid (EDTA). The Brecher-Cronkite phase technique was used (3).

Plasma prothrombin times were determined on blood collected in 0.1 vol 3.8 per cent sodium citrate by the methods of Quick (4) and of Ware and Stragnell (5). True prothrombin assays were done by a one-stage technique (6). Prothrombin times on serum were determined after incubation of a $2 \mathrm{ml}$ clot in a $12 \times 75 \mathrm{~mm}$ Pyrex tube for 1 hour at $37^{\circ} \mathrm{C}$. Consumption of prothrombin was stopped at that point by adding $0.9 \mathrm{ml}$ of serum to $0.1 \mathrm{ml} 3.8$ per cent sodium citrate. The technique of Ware and Stragnell was used.

Cephalin times were done on citrated plasma by adding $0.1 \mathrm{ml}$ optimal dilution of cephalin, prepared by the technique of Bell and Alton (7), and $0.1 \mathrm{ml}$ of $0.025 \mathrm{M}$ calcium chloride to $0.1 \mathrm{ml}$ plasma. The plasma was glassactivated by incubating $0.1 \mathrm{ml}$ in a new $12 \times 75 \mathrm{~mm}$ Pyrex tube for 3 minutes at $37^{\circ} \mathrm{C}$ before performing the test.

Fibrinogen levels were measured in the EDTA plasma by the technique of Ratnoff and Menzie (8). Thromboplastin screening tests were done by the technique of Hicks and Pitney (9), using the Bell and Alton cephalin. Thromboplastin generation tests were done by the technique of Biggs and Macfarlane (10). Cephalin at optimal dilution was used as a platelet substitute except for experiments where the platelets themselves were being tested. Dilutions of the serum and the absorbed plasma reagents were made as outlined in the Results section.

Factor $V$ levels were assayed by the technique of Borchgrevink, Pool and Stormorken (11) and also with the use of aged oxalate plasma as substrate (12). In this and all other clotting factor assays, the values are reported as percentage activity related to the control value before the experiment began.

Factor VIII (antihemophilic globulin) was assayed by the technique of Bergna (13) with the following modifications: Serum from clotted whole beef blood was used as a source of Factor IX, Factor X and Factor V. Outdated blood bank plasma from blood collected in acid citrate dextrose solution was used as the substrate on which the amount of plasma thromboplastin generated was assayed. In all assays, appropriate dilutions of plasma were made so that clotting times of the test plasmas would fall in the central part of the curve provided by dilutions of the control plasma $(1: 500,1: 1,000$, $1: 2,000$, and $1: 4,000)$. In one experiment, Factor VIII was measured by the cephalin time technique of Langdell, Wagner and Brinkhous (14) using plasma from a proven classical hemophiliac as substrate.

\section{RESULTS}

Physiological effect. Table I presents the changes in blood pressure caused by the two drugs at doses of 3 and $5 \mathrm{mg}$ per $\mathrm{kg}$, both with and without prior heparinization. Analysis of these data reveals that the rapid injection of either drug induces a profound hypotension, that the reduced blood pressure persists for several minutes, and that the degree of shock is not influenced by the presence or absence of heparin. Although these effects were more severe and more consistent with protamine than with Polybrene, the differences were small and not statistically significant.

The character of the changes in blood pressure was the same with both drugs. Alterations in pulse were also identical. There was a brief tachycardia followed by a protracted bradycardia. Electrocardiographic tracings in these animals revealed no conduction abnormality with either drug.

Both drugs were capable of producing a pronounced slowing in respiration, at times amounting to apnea (Figure 1), followed by prolonged tachypnea. Again these changes were slightly

TABLE I

Comparison of Polybrene and protamine in blood pressure depressing effects

\begin{tabular}{|c|c|c|c|c|c|c|c|c|c|}
\hline $\begin{array}{l}\text { Expt. } \\
\text { no. }\end{array}$ & Dog no. & Drug & Dose & Heparinized & $\begin{array}{c}\text { Average mean BP } \\
\text { before injection }\end{array}$ & $\begin{array}{c}\text { Lowest mean BP } \\
\text { after injection }\end{array}$ & $\begin{array}{l}\text { Maximum drop } \\
\text { in mean BP }\end{array}$ & $\begin{array}{l}\text { Drop } \\
\text { in BP }\end{array}$ & $\begin{array}{l}\text { Duration of } \\
\text { significant } \\
\text { BP depression }\end{array}$ \\
\hline & & & $\mathrm{mg} / \mathrm{kg}$ & $3 \mathrm{mg} / \mathrm{kg}$ & $m m \mathrm{Hg}$ & $m m H g$ & $m m H g$ & $\%$ & $\min$ \\
\hline 1 & 1 & Polybrene & 3 & Yes & 135 & 55 & 80 & 60 & 4 \\
\hline 2 & 2 & Polybrene & 3 & Yes & 165 & 90 & 75 & 45 & 7 \\
\hline 3 & 1 & Protamine & 3 & Yes & 125 & 45 & 80 & 64 & 2 \\
\hline 4 & 2 & Protamine & 3 & Yes & 128 & 63 & 65 & 51 & $\overline{1}$ \\
\hline 5 & 3 & Polybrene & 5 & Yes & 105 & 105 & 0 & o & \\
\hline 6 & 4 & Polybrene & 5 & Yes & 130 & 20 & 110 & 85 & 3 \\
\hline 7 & 3 & Protamine & 5 & Yes & 135 & 55 & 80 & 60 & 26 \\
\hline 8 & 4 & Protamine & 5 & Yes & 150 & 50 & 100 & 67 & 23 \\
\hline 9 & 5 & Polybrene & 3 & No & 115 & 50 & 65 & 57 & 13 \\
\hline 10 & 6 & Polybrene & 3 & No & 120 & 50 & 70 & 58 & 5 \\
\hline 11 & 5 & Protamine & 3 & No & 110 & 40 & 70 & 64 & 5 \\
\hline 12 & 6 & Protamine & 3 & No & 115 & 80 & 35 & 30 & 10 \\
\hline 13 & 7 & Polybrene & 5 & No & 133 & 108 & 25 & 19 & 3 \\
\hline 14 & 8 & Polybrene & 5 & No & 120 & 20 & 100 & 83 & 17 \\
\hline 15 & ? & Protamine & 5 & No & 165 & 55 & 110 & 67 & 6 \\
\hline 16 & 8 & Protamine & 5 & No & 140 & 30 & 110 & 79 & 30 \\
\hline
\end{tabular}




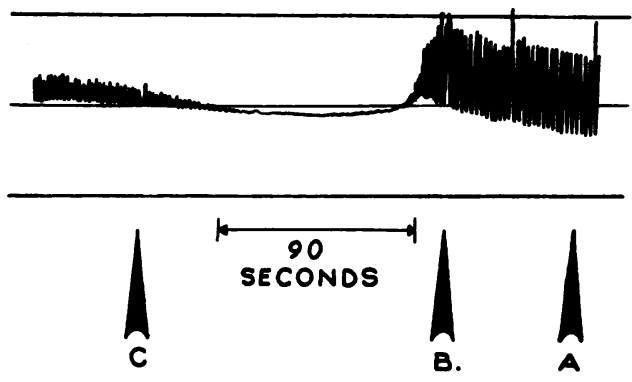

Fig. 1. Respiratory Changes induCEd by PROtAMine. A) Beginning of control period; B) injection of protamine; C) recovery period.

more pronounced with protamine but the difference is not significant.

Heparin-neutralizing effect. The comparative ability of protamine and Polybrene to neutralize heparin in blood in vitro was determined by adding human blood containing $25 \mu \mathrm{g}(2.5 \mathrm{U})$ of heparin per $\mathrm{ml}$ to parallel rows of tubes containing protamine and Polybrene in $0.1 \mathrm{ml}$ saline in quantities from 0 to $50 \mu \mathrm{g}$. The results of five such experiments are shown in Figure 2. Two points of significance stand out. Fifteen $\mu \mathrm{g}$ of Polybrene neutralizes $25 \mu \mathrm{g}$ of heparin, whereas 25 to $35 \mu \mathrm{g}$ of protamine is required. The results with Polybrene are definitely more consistent.

The disappearance of injected protamine and Polybrene from the circulating blood occurred at a rapid rate, as measured by ability of the blood to neutralize heparin in the titration test (Table II). As one would expect, the larger the dose given the higher the levels achieved, and the longer detectable amounts persisted. A second

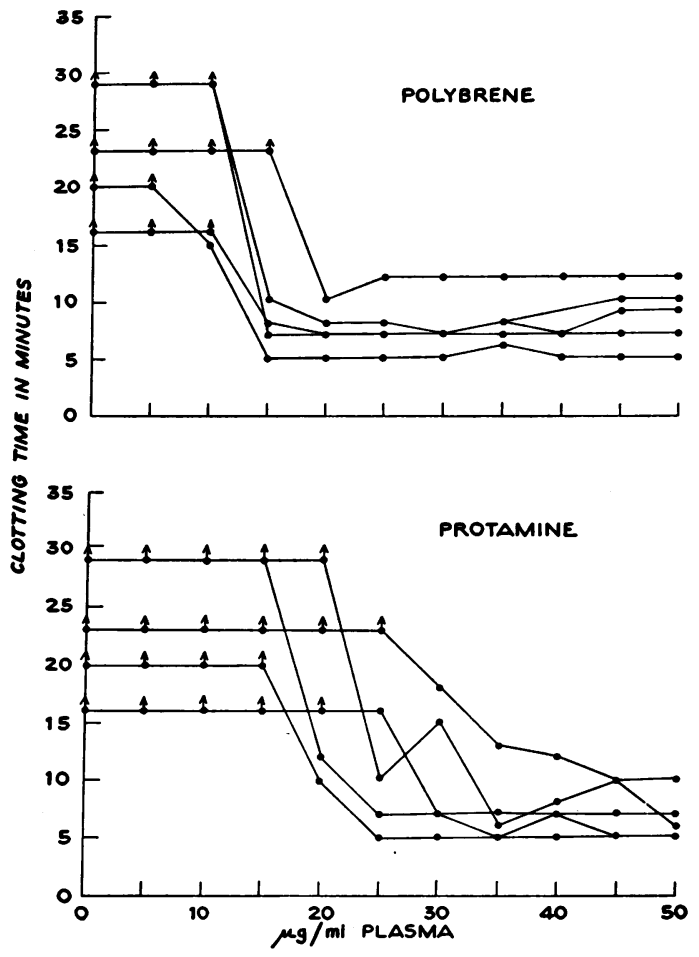

Fig. 2. Clotting times of heparinized blood in PRESENCE OF VARIoUs QUANTITIES OF Polybrene AND PROtamine. Arrows indicate that clotting time was longer than points recorded.

injection of Polybrene given 1 hour after the first (when all traces were gone from the blood) resulted in far greater concentrations. The apparently higher levels of Polybrene compared with those of protamine are very likely due to the fact, shown above, that it takes less of the former

TABLE II

Mean protamine and Polybrene levels after injection *

\begin{tabular}{|c|c|c|c|c|c|c|c|}
\hline \multirow{2}{*}{$\begin{array}{c}\text { Heparin } \\
\text { neutralizer }\end{array}$} & \multirow{2}{*}{$\begin{array}{l}\text { Whole } \\
\text { blood or } \\
\text { plasma }\end{array}$} & \multirow[b]{2}{*}{ Dose } & \multirow{2}{*}{$\begin{array}{l}\text { No. of } \\
\text { expts. }\end{array}$} & \multicolumn{4}{|c|}{ Minutes after injection } \\
\hline & & & & 2 & 5 & 10 & 20 \\
\hline & \multicolumn{3}{|c|}{$m g / k g$} & \multicolumn{2}{|c|}{$\mu g$} & \multicolumn{2}{|c|}{$\mu g$} \\
\hline 1 Polybrene & Blood & 5 & 3 & 25 & 8 & 2 & 0 \\
\hline 2 Protamine & Blood & 5 & 3 & 25 & 10 & 0 & 0 \\
\hline 3 Polybrene & Blood & 3 & 2 & 20 & 5 & 0 & 0 \\
\hline 4 Protamine & Blood & 3 & 3 & 8 & 0 & 0 & 0 \\
\hline 5 Polybrene & Blood & 2 & 2 & 5 & 0 & 0 & 0 \\
\hline 6 Protamine & Blood & 2 & 3 & 5 & 0 & 0 & 0 \\
\hline 7 Polybrene & Plasma & 5 & 9 & $23 \pm 6 \dagger$ & $13 \pm 5$ & $8 \pm 5$ & $2 \pm 3$ \\
\hline 8 Polybrene & Plasma & $5 \ddagger$ & 5 & $48 \pm 14$ & $34 \pm 9$ & $23 \pm 8$ & $16 \pm 5$ \\
\hline
\end{tabular}

* The figures quoted in the table represent the maximum amount of heparin $(\mu \mathrm{g})$ neutralized by $1 \mathrm{ml}$ of blood or plasma.

$\dagger$ Standard deviation.

$\ddagger$ Second injection 60 minutes after the first one. 
to neutralize a given amount of heparin. The close similarity in the amount of heparin neutralized by $1 \mathrm{ml}$ of whole blood (line 1 , Table II) and by $1 \mathrm{ml}$ of plasma (line 7, Table II) at any given time after the injection of Polybrene is very interesting. For present purposes it is of importance only that the rate of disappearance was the same by either technique. It seems worth commenting, however, that the use of plasma has a number of advantages: the test can be done at leisure, smaller amounts of blood are needed, and the added antiheparin effect of red blood cells and platelets is eliminated. The elimination of antiheparin effect of the cellular elements may explain why the antiheparin effect of $1 \mathrm{ml}$ of plasma is no greater than that of $1 \mathrm{ml}$ of blood (containing approximately $0.5 \mathrm{ml}$ of plasma). The close agreement of the antiheparin effect of $1 \mathrm{ml}$ of whole blood containing Polybrene with that of $1 \mathrm{ml}$ of plasma has been confirmed by simultaneous titrations on the same blood sample. It has not been possible to detect Polybrene in the red cells.

Effect on blood coagulation. The results of the injections on the clotting time of whole blood are shown in Figure 3. Despite the marked variability in the response of individual dogs, a consistent pattern emerged. One minute after injection there was a marked shortening of the clotting time while at 2 minutes it was markedly prolonged over control values. There was a rough correlation between the degree of effect and the dose of heparin antaganist administered. Prior injection of heparin lessened the effect. Many of the 2-minute samples never clotted de-

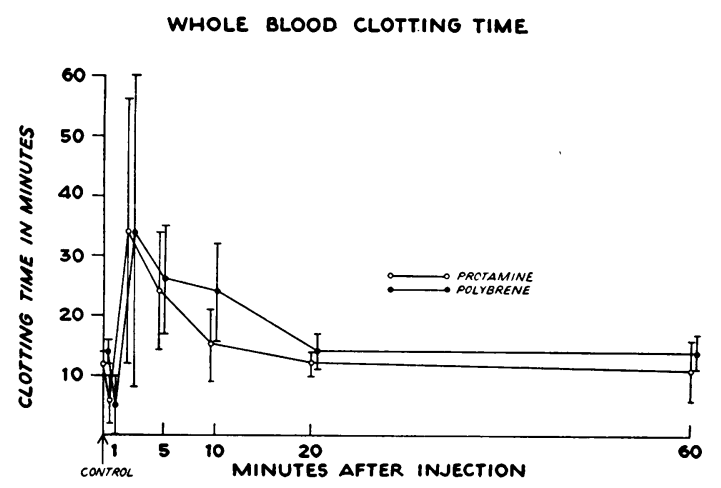

Fig. 3. Whole blood clotting time. In this and all subsequent figures the vertical lines represent 1 standard deviation.

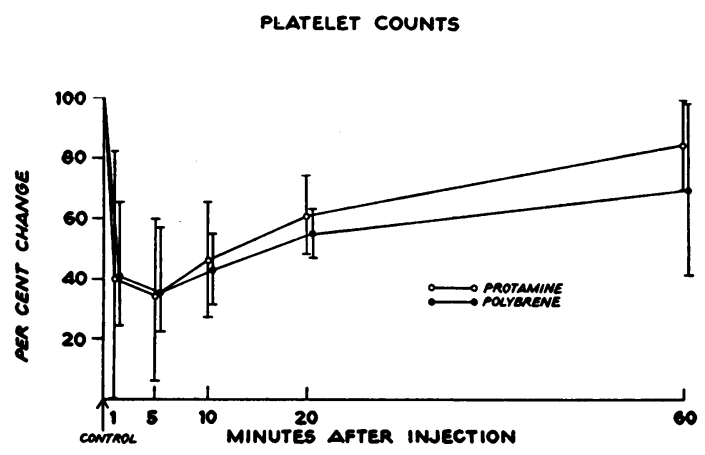

Fig. 4. Platelet counts.

spite the fact that addition of $0.1 \mathrm{vol}$ of undiluted (1 per cent) Polybrene or protamine in vitro to blood could not prolong its clotting time to that extent. This was the first clue that these heparin neutralizers were doing more to the blood coagulation system than could be explained by their known weak anticoagulant effect. There was no significant difference between the two heparin antagonists in these results.

Platelet counts showed that both drugs caused an immediate profound thrombocytopenic effect with a slow return to normal levels (Figure 4). There was no significant difference between the two. Fibrinogen levels were variably reduced to a minor degree.

Plasma prothrombin times (Quick and WareStragnell) were prolonged to an insignificant degree by both substances. True prothrombin assays showed no change. Serum prothrombin times (Figure 5) showed a profound effect. Prothrombin consumption was completely in-

ONE HOUR SERUM PROTHROMBIN ACTIVITY

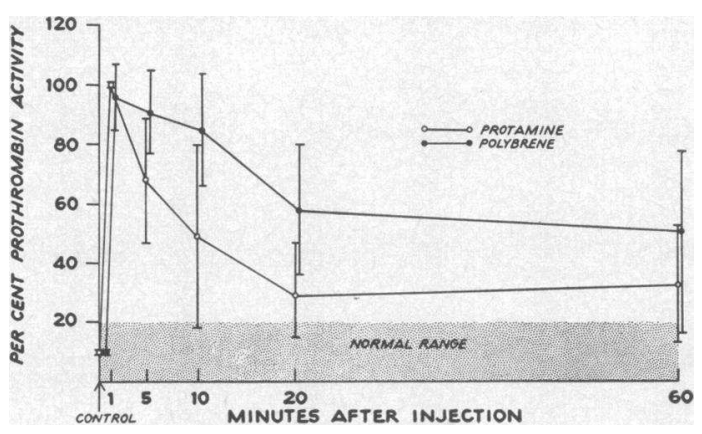

Fig. 5. ONE-HOUR SERUM PROTHROMBIN ACTIVITY. Per cent prothrombin activity in serum 1 hour after clotting as related to activity of plasma from same blood sample. 
hibited immediately after injection, and was still abnormal 60 minutes later, long after the platelet count had returned above levels at which it could be responsible for the results. Although the difference was not statistically significant, as shown by the standard deviations in the figure, the effect of Polybrene appeared to be greater than that of protamine.

Cephalin times (Figure 6) also showed a marked abnormality, and were not back to the control levels by the end of an hour. Again Polybrene showed the greatest effect although the differences do not appear to be statistically significant. The changes in clotting time, prothrombin consumption, and cephalin times were greater and more persistent than could possibly be explained by the anticoagulant effect of circulating protamine or Polybrene. Proof that the abnormality was due to a clotting factor deficiency rather than to a circulating anticoagulant is provided in Figure 7 , which shows the cephalin times obtained when control plasma was mixed in varying proportions with samples obtained 2, 10 and 60 minutes after Polybrene. In the 2-minute sample, when the Polybrene level was at its highest, a slight anticoagulant effect is apparent in that 10 per cent of the 2-minute plasma prolonged the cephalin time of the control plasma, but even with the 2-minute sample, 10 per cent of control plasma had a significant shortening effect. The ability of a small amount of normal plasma to correct the abnormal plasma (characteristic of a clotting factor deficiency) is clearly apparent with the 10- and 60minute samples.

The abnormal results with whole blood clotting times, cephalin times, and prothrombin consumptions (compared with the normal prothrombin

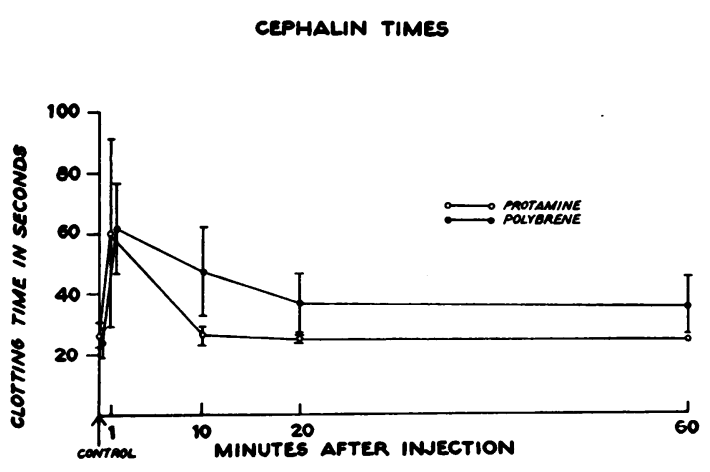

Fig. 6. Cephalin times.

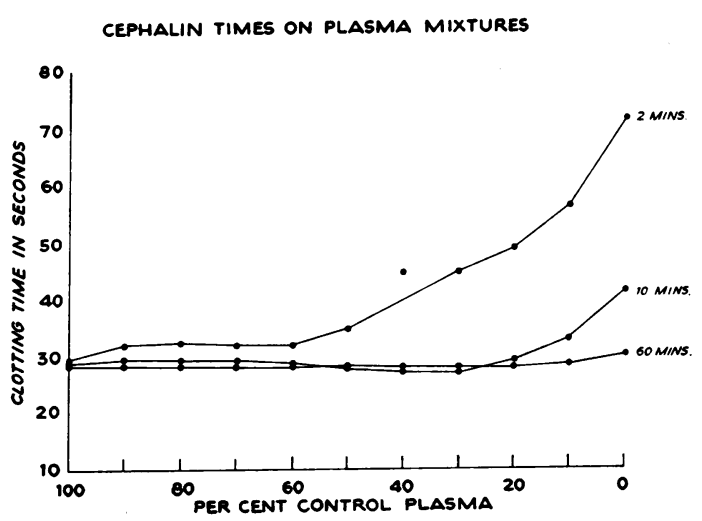

Fig. 7. Cephalin times on plasma mixtures. Control plasma was mixed in varying proportions with plasma from a sample removed 2 minutes after the injection of Polybrene, and cephalin times of the mixtures were determined. Mixtures of control plasma with plasma obtained 10 and 60 minutes after Polybrene were similarly checked.

times) indicated that the clotting factor deficiency was in the first stage of coagulation, the stage of thromboplastin generation. Despite this, thromboplastin screening and generation tests by the standard techniques showed little or no abnormality. Evidence that thromboplastin generation was impaired, however, was obtained using highly diluted reagents.

Dog platelets tested in the thromboplastin generation test (TGT) at intervals after injection of

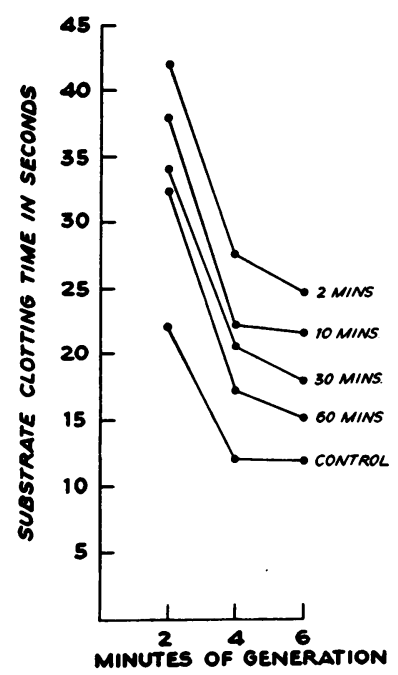

Fig. 8. Thromboplastin generation test (CONTROL SERUM AND CEPHALIN). The effects of absorbed plasma obtained before and at various intervals after Polybrene are compared in the TGT. 
TABLE III

Factor $V$ levels (per cent control) after injection of Polybrene $(5 \mathrm{mg} / \mathrm{kg})$

\begin{tabular}{lccccccc}
\hline \hline & & \multicolumn{5}{c}{ Minutes after injection } \\
\cline { 3 - 7 } Method & $\begin{array}{c}\text { No. of } \\
\text { expts. }\end{array}$ & Control & 2 & 5 & 10 & 20 & 60 \\
\hline Ref. 11 & 7 & 100 & $171 \pm 47^{*}$ & $173 \pm 50$ & $163 \pm 46$ & $141 \pm 39$ & $90 \pm 37$ \\
Ref. 12 & 1 & 100 & 200 & 168 & 100 & \\
\hline
\end{tabular}

* Standard deviation.

Polybrene remained qualitatively normal, even when employed as washed whole platelets at the suboptimal concentration of 100,000 per $\mathrm{mm}^{3}$.

Serum is customarily employed in the TGT on human blood at a dilution of $1: 10$. Using control dog serum it was demonstrated that, in this animal, serum could be diluted as high as 1:40 and still produce a potent thromboplastin in 6 minutes. The post-Polybrene samples generated thromboplastin normally at this dilution.

Citrated plasma absorbed with aluminum hydroxide is used to provide Factor VIII and Factor $\mathrm{V}$ for thromboplastin generation. The standard test employs a dilution of 1:5. At optimal dilution for the $\operatorname{dog}(1: 40$ also $)$ the absorbed plasma from blood samples taken after Polybrene showed a marked defect, which gradually returned toward normal, but was still far from the control levels at the end of 1 hour (Figure 8).

It was unlikely that the defect in absorbed plasma was due to a Factor $\mathrm{V}$ deficiency, since this would have prolonged the prothrombin times. Specific assays for Factor $\mathrm{V}$ showed the rather unexpected result that Factor $\mathrm{V}$ levels were actually increased by Polybrene (Table III).

By exclusion we were thus left with a Factor VIII deficiency as the explanation of our abnormal clotting tests. Direct assays for Factor VIII by a very sensitive technique proved that this was indeed true, and the specificity of the results was corroborated by an assay using plasma from a patient with classical hemophilia as the substrate. The severe depression of antihemophilic globulin levels and the prolonged duration of the defect are very striking (Table IV, line 1). Control levels of Factor VIII in the dogs used were more than five times as high as the average of our normal humans. This explains why the antihemophilic globulin defect became apparent in the TGT only in systems using highly diluted plasmas.

A slower infusion of the same dose of Polybrene (Table IV, line 2) resulted in a slower, milder depression of Factor VIII levels with return toward normal beginning by the end of 1 hour. A second rapid injection given 1 hour after the first (Table IV, line 3 ), resulted in no further fall in Factor VIII levels despite the fact that simultaneous assays of Polybrene levels showed them to be much higher than those after the first injection (Table II, line 8). When heparin (6 $\mathrm{mg}$ per $\mathrm{kg}$ ) was injected prior to the Polybrene (two experiments) there was no change in Factor VIII from the control value. When heparin was injected 10 minutes after Polybrene (two experiments) it had no effect on the course of the low Factor VIII levels.

\section{DISCUSSION}

The demonstration that a synthetic basic compound of large molecular weight (Polybrene)

TABLE IV

Factor VIII levels (fer cent control) after injeciion of Polybrene $(5 \mathrm{mg} / \mathrm{kg}$ )

\begin{tabular}{|c|c|c|c|c|c|c|c|}
\hline \multirow{2}{*}{$\begin{array}{c}\text { Rate of } \\
\text { injection } \\
\text { of Polybrene }\end{array}$} & \multirow{2}{*}{$\begin{array}{l}\text { No. of } \\
\text { expts. }\end{array}$} & \multirow[b]{2}{*}{ Control } & \multicolumn{5}{|c|}{ Minutes after injection } \\
\hline & & & 2 & 5 & 10 & 20 & 60 \\
\hline $\begin{array}{ll}1 & \text { Fast } \\
2 & \text { Slow* } \\
3 & \text { Fast } \dagger\end{array}$ & $\begin{array}{l}7 \\
6 \\
4\end{array}$ & $\begin{array}{r}100 \\
100 \\
14\end{array}$ & $\begin{array}{l}22 \pm 28 \\
82 \pm 23 \\
13\end{array}$ & $\begin{array}{c}8 \pm 8 \\
50 \pm 27 \\
12\end{array}$ & $\begin{aligned} & 7 \pm 5 \\
& 26 \pm 30 \\
& 12\end{aligned}$ & $\begin{array}{l}10 \pm 8 \\
29 \pm 30 \\
11\end{array}$ & $\begin{array}{c}8 \pm 2 \\
60 \pm 32\end{array}$ \\
\hline
\end{tabular}

* The undiluted Polybrene was infused by a slow drip during the first 10 minutes of sampling.

$\dagger$ Given 60 minutes after a fast injection of Polybrene. 
could be used to neutralize heparin in vivo (15) has led to a number of studies to compare its effects with those of the earlier used heparin antagonist, protamine (16-18). In two of these studies, it was concluded that Polybrene is to be preferred because, following its use, less postoperative blood loss was noted. These studies discounted (perhaps erroneously) the possibility that the lesser degree of postoperative bleeding might be due to improved techniques of patient management and did not consider the possibility that the dose of Polybrene selected may have come closer to exact neutralization of heparin than did the dose of protamine previously used.

One criticism of protamine (16) was that it was unstable and varied in potency. The references quoted in support of this idea were to preparations of protamine available a number of years ago, and this objection is no longer valid according to our experience.

Since early work with Polybrene demonstrated that it could produce the same side effects as protamine (15), we performed a series of experiments on dogs in which the magnitude of the effects of the two heparin antagonists could be compared with some exactness. Because protamine clearly had been shown to have an anticoagulant effect in vitro $(19,20)$, we were particularly interested in finding out whether this was demonstrable after in vivo injection and whether the findings would be similar with Polybrene.

The results reported above show that there is a marked variability in the responses of individual dogs. Nonetheless, it is apparent that in comparable doses protamine and Polybrene show the same tendency to produce marked hypotension, tachycardia followed by bradycardia, and slowing of respiration followed by tachypnea. Similarly, both drugs demonstrated an equal tendency to induce thrombocytopenia and an unexpected defect of the plasma coagulation system. Although studies demonstrated that Polybrene was a more powerful heparin-neutralizing agent than protamine, it also had a slightly more depressing effect on the blood clotting system.

Polybrene was demonstrated to disappear from the circulating blood very rapidly, as previously had been shown for protamine (21). The mechanism by which they disappear is unknown but their site of uptake appears to have a limited capacity in view of the much higher blood levels achieved when a second injection followed the first. The coagulation defect induced by both drugs persisted long after the heparin antagonists had left the blood stream, and could not be entirely explained by their anticoagulant effect nor by the induced thrombocytopenia. The prolonged whole blood clotting and cephalin times and the poor prothrombin consumption, as compared with normal plasma prothrombin times, suggested that a defect had been induced in the first stage of blood coagulation. Although standard thromboplastin generation and screening tests failed to establish this, more sensitive tests clearly demonstrated that a striking deficiency of Factor VIII had been induced. The animals bled persistently at the site of vessel cannulation, and it thus appears that a temporary coagulation defect had been induced analogous to classical hemophilia.

The mechanism by which Factor VIII is removed from the circulating blood is unclear. The magnitude and duration of the decrease in Factor VIII levels is related to the dose of Polybrene given and the speed at which it is injected. This suggests that the depression of Factor VIII depends on the blood level of Polybrene achieved and that the two may form a complex which is then removed from the circulation. Evidence against this supposition, however, is provided by the fact that a second injection of Polybrene, given while Factor VIII was still at a very low level, did not succeed in reducing the concentration of the coagulation factor further, even though much higher levels of Polybrene appeared in the circulating blood than those following the first dose.

Further objection to the hypothesis of direct interaction between Polybrene and Factor VIII comes from the fact that such a reaction cannot be demonstrated in the test tube. Protamine inhibits thromboplastin generation in vitro but it has not been possible to demonstrate that it acts by opposing Factor VIII. In fact, Shanberge (20) believes it may react with Factor IX. His evidence for this was that serum containing Factor IX appeared to promote thromboplastin generation in the presence of protamine. Shanberge's evidence does not prove direct interaction between protamine and Factor IX; moreover, Hougie (19) was unable to confirm Shanberge's claim that serum had a specific antagonistic action against 
protamine in the TGT. In any case, no evidence can be offered to show that protamine and Factor VIII react with each other in vitro. One could speculate that a protamine- or Polybrene-Factor VIII complex does form, that in vivo it is cleared from the circulation, but that in vitro it remains available for products of beginning coagulation to attract Factor VIII and thus disrupt the complex The best argument against the direct interaction between Polybrene and Factor VIII remains the failure of a second dose of Polybrene to lower the Factor VIII levels further.

A second possible explanation for the disappearance of Factor VIII is that it is consumed by beginning intravascular coagulation. This possibility gains weight when we consider the fact that the whole blood clotting times momentarily shortened before they became prolonged, that prior injection of heparin prevented the loss of Factor VIII and that the platelet count fell. On the other hand, intravascular coagulation should consume Factor V, prothrombin and fibrinogen, but these did not decrease. Moreover, thrombocytopenia occurs even with prior heparin. One might speculate that the process of intravascular coagulation was interrupted by the anticoagulant action of Polybrene at some point between the consumption of Factor VIII and that of the other factors mentioned or that just enough thrombin evolved to destroy Factor VIII alone. No evidence can be offered that this is possible.

It seems most likely at the moment that Factor VIII disappears, not by means of direct combination with Polybrene and not as a result of beginning intravascular coagulation, but in a more indirect manner. Failure of a second injection of Polybrene to lower the Factor VIII level further suggests that some compound intermediary in the reaction may have been depleted by the first injection.

The changes in Factor $\mathrm{V}$ following injection of Polybrene were in contrast to those in Factor VIII. The levels rose sharply to nearly twice the control values and then returned to normal over a period of 60 minutes. No obvious explanation for these changes is apparent. When Polybrene is added to plasma in vitro, apparent levels of Factor $\mathrm{V}$ decrease as the quantity of Polybrene is raised. The rise in Factor V ap- pears to be a true one, since one of the assays used is believed to fully activate Factor $\mathrm{V}$ before it is measured (11).

The findings presented here have definite practical implications. Andersen, Mendelow and Alfano have observed (22) that clotting times of whole blood after heart-lung bypass and neutralization of heparin are frequently longer than the control preoperative values. They believe that greater abnormalities occur with larger doses of heparin antagonists. These findings suggest that our observations in dogs are probably a reflection of what occurs in human patients. The clotting defect induced will vary in degree according to the amount of Polybrene or protamine that is administered in excess of that which is neutralized by the available heparin. In the experiments reported here, a dose of Polybrene of $5 \mathrm{mg}$ per $\mathrm{kg}$ was administered to ensure that the clotting defect would be sufficiently severe for analysis. Most surgical teams give Polybrene in a dose approximately equal to that which has been used for heparin. It is highly unlikely under these conditions that an excess of Polybrene as high as 1 $\mathrm{mg}$ per $\mathrm{kg}$ would be given. Such an excess would produce a mild and transient clotting defect of little clinical significance. Larger doses, however, would carry a real risk; and the chief danger is that the surgeon, confronted by a patient with a prolonged clotting time and excessive bleeding, will give additional doses of Polybrene or protamine under the assumption that heparin has not yet been completely neutralized. Moreover, there are still recommendations appearing in the current literature that doses of protamine or Polybrene can or should be four to eight times the dose of heparin which had been administered (23). Most surgical teams have arrived empirically at a dose of heparin antagonist which works for them. It is our belief that this dose should not be exceeded unless it can be demonstrated in the test tube that added protamine or Polybrene will shorten the clotting time of the patient's blood. ${ }^{3}$

\footnotetext{
${ }^{3} \mathrm{Dr}$. John Osborn at the Presbyterian Hospital in San Francisco suggests a very simple way to do this. He dilutes Polybrene 1:40 with saline in a syringe, then transfers 1 drop to an empty $12 \times 75 \mathrm{~mm}$ glass tube, 2 drops to a second, 3 drops to a third, and leaves a fourth tube empty. One $\mathrm{ml}$ blood is added to each tube, mixed with the Polybrene and observed for clotting at room
} 
We hasten to add that we do believe it important that all traces of unneutralized heparin be eliminated in these cases (23).

Since protamine or Polybrene in appropriate doses can neutralize heparin equally well, and since they demonstrate the same undesirable side effects to approximately the same degree, there is little reason to prefer one to the other. It would seem, therefore, that the choice of drug is less important than the choice of dosage, particularly in regard to avoiding the production of a paradoxical prolongation of clotting by either agent.

\section{SUM MARY}

Two heparin antagonists, protamine and Polybrene, have been compared in a series of parallel experiments in vivo and in vitro. The effects of both drugs on blood pressure, pulse, respiration, platelet counts, and blood coagulation are so similar that there is little reason to prefer one over the other. Polybrene neutralizes more heparin than a comparable dose of protamine, but the degree of undesirable side effects appears to correlate with heparin-neutralizing ability.

Large doses of either drug have the unexpected capacity of inducing a striking deficiency of Factor VIII in dogs. Factor V levels are, in contrast, elevated. The mechanism by which these effects are produced is not clear, but it seems probable that the reaction is a nonspecific one and unrelated to the well known anticoagulant effects of these heparin antagonists. It is likely that a similar antihemophilic globulin deficiency may be induced in human patients by the use of excessive doses of heparin antagonists following open heart surgery. The dangers of this situation are obvious, and a plea is made for judicious use of the heparin antagonists.

\section{REFERENCES}

1. Perkins, H. A., Acra, D. J., and Rolfs, M. R. Duration of coagulation abnormalities following in vivo neutralization of heparin by protamine and Polybrene (abstract). J. clin. Invest. 1960, 39, 1016.

2. Perkins, H. A., Acra, D. J., and Rolfs, M. R. Hemophilia induction by intravenous Polybrene (abstract). Clin. Res. 1961, 9, 94.

temperature every few minutes. This is a simplification of a method we have previously reported (24).
3. Brecher, G., Schneiderman, M., and Cronkite, E. P. The reproducibility and constancy of the platelet count. Amer. J. clin. Path. 1953, 23, 15.

4. Quick, A. J. Hemorrhagic Diseases. Philadelphia, Lea and Febiger, 1957.

5. Ware, A. G., and Stragnell, R. An improved onestage prothrombin method. Amer. J. clin. Path. 1952, 22, 791.

6. Alexander, B. One-stage method for specific prothrombin determination in The Coagulation of Blood. Methods of Study, L. M. Tocantins, Ed. New York, Grune and Stratton, 1955, p. 94.

7. Bell, W. N., and Alton, N. G. A brain extract as a substitute for platelet suspensions in the thromboplastin generation test. Nature (Lond.) 1954, 174, 880.

8. Ratnoff, O. D., and Menzie, C. A new method for the determination of fibrinogen in small samples of plasma. J. Lab. clin. Med. 1951, 37, 316.

9. Hicks, N. D., and Pitney, W. R. A rapid screening test for disorders of thromboplastin generation. Brit. J. Haemat. 1957, 3, 227.

10. Biggs, R., and Macfarlane, R. G. Human Blood Coagulation and Its Disorders, 2nd ed. Oxford, England, Blackwell, 1957.

11. Borchgrevink, C. F., Pool, J. G., and Stormorken, H. A new assay for Factor $\mathrm{V}$ (proaccelerin-accelerin) using Russell's viper venom. J. Lab. clin. Med. 1960, 55, 625.

12. Stefanini, M. New one-stage procedures for the quantitative determination of prothrombin and labile factor. Amer. J. clin. Path. 1950, 20, 233.

13. Bergna, L. J. A simple method for the assay of Factor VIII. Blood 1960, 15, 637.

14. Langdell, R. D., Wagner, R. H., and Brinkhous, K. M. Estimation of antihemophilic activity by the partial thromboplastin time technic in The Coagulation of Blood. Methods of Study, L. M. Tocantins, Ed. New York, Grune and Stratton, 1955, p. 72.

15. Weiss, W. A., Gilman, J. S., Catenacci, A. J., and Osterberg, A. E. Heparin neutralization with Polybrene administered intravenously. J. Amer. med. Ass. 1958, 166, 603.

16. Blumberg, J. B., Winterscheid, L. C., Dillard, D. H., Vetto, R. R., and Merendino, K. A. The clinical use of Polybrene as an antiheparin agent in open heart surgery. J. thorac. Surg. 1960, 39, 330.

17. Keats, A. S., Cooley, D. A., and Telford, J. Relative antiheparin potency of Polybrene and protamine in patients undergoing extracorporeal circulation. J. thorac. Surg. 1959, 38, 362.

18. Lillehei, C. W., Sterns, L. P., Long, D. M., and Lepley, D., Jr. Comparative study of Polybrene and protamine for heparin neutralization in open heart surgery. Ann. Surg. 1960, 151, 11.

19. Hougie, C. Anticoagulant action of protamine sulphate. Proc. Soc. exp. Biol. (N. Y.) 1958, 98, 130. 
20. Shanberge, J. N. The effect of protamine on thromboplastin generation in The International Society of Hematology, Proceedings of the Seventh Congress. New York, Grune and Stratton, 1960, vol. 2, pt. 2, p. 1030 .

21. Jaques, L. B. A study of the toxicity of the protamine, Salmine. Brit. J. Pharmacol. 1949, 4, 135.

22. Andersen, M. N., Mendelow, M., and Alfano, G. A. A comparative study of heparin neutralization and the danger of blood clotting abnormalities with protamine and Polybrene. J. thorac. Surg. 1960, 39, 613.

23. Rothnie, N. G., and Kinmonth, J. B. Bleeding after perfusion for open heart surgery. Importance of unneutralized heparin and its proper correction. Brit. med. J. 1960, 1, 73.

24. Perkins, H. A., Osborn, J. J., Hurt, R., and Gerbode, F. Neutralization of heparin in vivo with protamine; a simple method of estimating the required dose. J. Lab. clin. Med. 1956, 48, 223. 